Prepared for the PPMR Symposium on "Trust and Public Management: The Frontier of Research."

\title{
Government trust, social trust, and citizens' risk concerns: Evidence from crisis management in China
}

\begin{abstract}
Citizens' trust in government and others is crucial to the perceptions of social risks. In this study we examine the effects of institutional and social trust on citizens' risk perceptions. Our analysis of a 2013 national survey conducted in thirty provincial capitals in China reveals that risk perceptions focus on two factors, public emergencies (e.g., traffic accidents) and public health threats (e.g., food safety). We found that only citizens' trust in central government was significantly negatively correlated with perceived emergencies, while trust in local government was marginally positively correlated with emergency perceptions. Social trust was not correlated with perceptions of emergencies, and none of the three trust variables are significantly correlated with perceived health threats. Our results reveal that the demographic variables gender, age, education, media exposure and religious belief are all relevant for citizens' risk perceptions.
\end{abstract}




\section{Introduction}

The world is increasingly perceived as a dangerous place to live; indeed, we are said to live in a risk society (Beck, 1992). Increasingly, political-administrative systems and citizens have to cope with natural disasters and man-made emergencies. Citizens are more and more concerned about societal risks and call on governments to take action to prevent and handle crises and disasters. The dynamic interactions between governance capacity and governance legitimacy are central to crisis management, with governance legitimacy receiving increasing attention in the literature (Christensen, Lægreid, \& Rykkja, 2016). Governance capacity focuses on the performance of different levels of government in preventing and handling crises, while governance legitimacy in crisis management mainly refers to a government's reputation and citizens' trust, which is part of what is called societal or horizontal accountability (Bovens, 2007; Schillemans, 2008). Without citizens' trust in government, crisis management cannot succeed (Christensen \& Lægreid, 2005). Social trust, namely peoples' trust in other people, is also said to play a pivotal role in crisis management, even though it is not entirely clear how and to what degree (Siegrist \& Cvetkovich, 2000).

In this article we set out to examine the nexus of trust and crisis management by drawing on two organization theory perspectives - a structural and a cultural one (Christensen et al., 2007). We specifically examine the effects of government trust and social trust on citizens' risk concerns in the context of China, which suffers frequent natural disasters and man-made emergencies (Chen, 2016), compounded by a deficit of trust during the radical social transition that has taken place over the past decades ( $\mathrm{Lu} \&$ Xue, 2016). There are, moreover, substantial disparities between citizens' trust in central and in local government (Chen, 2017; Li, 2016; Wu \& Wilkes, 2017), which are quite the contrary to that in Western countries; we compare the impact of these different levels of trust on risk perceptions. The swift pace of change and the rapid urbanization of China have brought about major changes in societal structures (Yu \& Ma, 2016). Together with market-oriented reforms these have substantially undermined social ties 
and community spirit, which in turn may potentially undermine trust and social capital. We would thus expect social trust to have a significant impact on citizens' concerns about crises.

The main research questions we focused on are the following:

- What characterizes the risk perceptions of citizens in China?

- What characterizes the relationships between different types of trust and risk perceptions and what is the relative importance of individual characteristics in this respect?

- How can we explain variance in risk perceptions based on different organization theory perspectives?

To answer these questions, we have used a 2013 national survey in China, which gathered data from thirty provincial capital cities. The results reveal that risk perceptions are grouped into public emergencies (e.g., traffic accidents) and public health threats (e.g., food safety). We found that only citizens' trust in central government was negatively correlated with perceived emergencies, while trust in local government was positively correlated with emergency perceptions. Social trust was not correlated with perceptions of emergencies, and none of the three trust variables are significantly correlated with perceived health threats. The findings also show that some demographic variables (e.g., gender, age, education) are key antecedents of risk perceptions. These results help to understand the linkages between trust variables and risk perceptions.

In the remainder of this article, after introducing our theoretical basis, we present the data and methods used in the study, including a set of expectations. This is followed by the main empirical results and a discussion/analysis. We conclude by discussing theoretical contributions and policy implications, identifying some limitations and making suggestions for future avenues of research. 


\section{Theory and Hypotheses}

\section{Risk perceptions}

Given the complexity and uncertainty of new technologies such as nuclear, biological, and chemical engineering (e.g., nuclear power plant, para-xylene (PX) manufacture, garbage incinerators, genetically modified food processing) (Beck, 1992), the public is understandably very concerned about the threats they may pose to human safety (Slovic, 1987). People are skeptical and worried about phenomena they do not know much about or which may seem frightening or threatening, but overcautious reactions and groundless concerns about social risks may also cause panic and disorder in society; this may in turn undermine effective crisis management (Christensen, Lægreid, \& Rykkja, 2016). In the case of China, as in many other countries, citizens are often mobilized to engage in collective actions to boycott new nuclear and chemical technologies (e.g., the 2007 PX project in Xiamen). Sometimes such actions are scientifically justified and cautiously implemented, but in many cases they are driven by understandable worries based on experience of numerous disasters and threats. It is thus imperative to examine the key drivers of risk perceptions, which may help the government effectively manage public attitudes and perceptions in crisis management, but may also potentially undermine them.

Social risks can arise from both natural disasters (e.g., earthquakes, hurricanes, forest fires, and floods) and man-made emergencies (e.g., environmental pollution, epidemics, and food contamination). Risk perceptions are "the judgements people make when they are asked to characterize and evaluate hazardous activities and technologies" (Slovic, 1987, p. 280). While objective evidence and experts' judgements are important, it is people's perceptions that may matter most in crisis response. Risk perceptions are complicated psychological and cognitive mechanisms, influenced by the dynamic relationship between governance capacity and legitimacy, which generate profound behavioral consequences for crisis management (Christensen, Lægreid, \& Rykkja, 2016). 
People's attitudes toward and perceptions of social risks are shaped by various factors, including but not limited to demographics, personality, predisposition, and social interaction. Most people without expertise or professional knowledge rely on their intuition, communication with people they trust or professional interpretations of events in the media to judge social risks, and in most cases their risk perceptions are exaggerated or distorted (Slovic, 1987). Risk may be especially amplified by media exposure (Wahlberg \& Sjoberg, 2000), which plays a key role in communicating, distorting, and misshaping risk messages (Kasperson, Renn, \& Slovic, 1988). It is important to acknowledge that "there is wisdom as well as error in public attitudes and perceptions" (Slovic, 1987, p. 285). In the following subsections we will elaborate on the impacts of government and social trust on risk perceptions, and develop testable hypotheses by using structural and cultural perspectives.

\section{Government trust and risk perceptions}

Easton (1965b) draws a distinction between diffuse and specific support in a political-administrative system. Diffuse support is about whether people have a general attitude of trust or distrust towards the system as such and its major institutions and actors, while specific support is about trust in specific institutions and actors (Easton, 1965b). The dynamics between the two are said to work like this: the higher the diffuse support, the less damaging single events, like crises, may harm the system, i.e. it creates 'high slack' or legitimacy in the system (Cyert \& March, 1963). Or on the contrary, low diffuse support will require a lot of specific support to enhance overall trust. So we can expect trust and crisis perceptions to work differently when trust and support are differentiated. This is relevant for the Chinese case.

Citizen trust in government plays a pivotal role in improving government work and consolidating public legitimacy (Christensen \& Lægreid, 2005; Van de Walle \& Bouckaert, 2003; Yang \& Holzer, 2006). While the role of government trust in performance measurement, civil service recruitment and policy compliance has been extensively documented, its importance in crisis management is relatively understudied. 
Public perceptions of social risks are largely shaped by citizens' trust and confidence in the government, which is primarily affected by government capacity and performance in preventing and handling crises, but also by more general cultural factors related to legitimacy. Citizens are less concerned about crises when government is well prepared, efficient, and responsive. Otherwise citizens will feel that they have to protect their own safety, and their risk perceptions will be higher. If citizens consider government credible and trustworthy, their perceptions of crises will be lower.

In the case of food safety, for instance, consumers' trust in specific actors in the food industry will significantly affect their general confidence in food safety (De Jonge et al., 2008). A recent study revealed that citizens' and civil servants' perceptions of crisis management in Norway are affected by both cultural and political variables (Christensen, Fimreite, \& Lægreid, 2011). The Nordic case suggests that "the perception of crises to a great extent is dependent on different dimensions of trust: social trust, citizens' trust in government, and mutual trust between government bodies" (Christensen, Fimreite, \& Lægreid, 2011, p. 583). A recent survey of twenty-six EU countries showed that impartial public administration is negatively related to public confidence in EU crisis management institutions, while social trust is less significant (Persson, Parker, \& Widmalm, 2017). These and other studies suggest that both government and social trust play indispensable roles in shaping risk perceptions, which are the focus of this study.

Governments at various levels are involved in crisis management, but their effects on citizens' risk perceptions may vary. The central government deals with general policies and guidelines for crisis management and only engages when crises escalate and go beyond the scope of specific jurisdictions (e.g., cross-boundary and cross-level crises), while in most cases it is local governments that respond to and handle crises. ${ }^{1}$ This may lead to the expectation that risk perceptions will correlate more closely with citizens'

\footnotetext{
${ }^{1}$ People very seldom are able to differentiate whether it is local government (in democracies elected in local elections) or regional/local branches of central government organizations that are responsible for preventing and handling crises locally. In the Chinese system this distinction is less relevant since agencies are structured similar across levels and ordinary citizens can usually distinguish among levels of local government.
} 
trust in local government than in central government. Citizens' trust also varies across government levels, and in China the public has a more favorable view of the central government than of local government (Chen, 2017; Li, 2016; Wu \& Wilkes, 2017). North American and many European citizens, on the other hand, trust local more than central government (Levi \& Stoker, 2000). Given the lingering disparities between citizens' trust in central and local government in China, it is interesting to compare the effects of central and local government trust on risk concerns. While the ramifications of generic government trust are meaningful, it is more relevant to disentangle the varying effects of citizen trust in different levels of government, which is not well covered in the existing literature.

\section{Social trust and risk perceptions}

Apart from government trust, social trust, namely people's trust in other people, may play an important role in crisis management. Although it is the government's job to prevent and respond to crises, citizens also have to rely on themselves and fellow residents, whom they know more or less, to survive and recover from crises (Christensen \& Aars, 2017). Mutual aid and reciprocal exchange among social actors play a crucial role in preventing and handling crises (Rothstein, 1998). Citizens rely on each other to collectively respond to social risks and emergencies, and mutual trust helps to lower transaction costs and facilitate cooperation.

We expect that citizens with a higher level of social trust are less likely to be concerned about social risks. The correlation between social trust and citizens' risk perceptions is particularly strong when they lack personal knowledge about hazards (Siegrist \& Cvetkovich, 2000). For instance, a lack of social trust is found to make consumers more worried about food safety (Sapp \& Bird, 2003). Social trust is also indirectly related to food safety perceptions shaped by consumers' trust in food industry actors such as farmers and manufacturers (Chen, 2013). Social capital, as seen by Putnam (2000), may enhance peoples' trust in others, often because they have both a higher level of interaction with others and more political and social resources. This in 
turn may enhance their ability to interpret and understand crisis situations.

\section{Theoretical perspectives and hypotheses}

The two perspectives used - structural and cultural - are taken from organization theory (Christensen et al., 2007). A structural perspective sees formal structures of public organizations as instruments for achieving goals, and it channels and influences the modes of thought and decision-making behavior of politicians and civil servants (Egeberg, 2012; Simon, 1957). Since our focus is on the citizens and their trust, the structural perspective is primarily connected to the relevance of governance capacity. How citizens experience the government capacity to handle crises and risks is therefore dependent on how the government is organized in this respect. Citizens will for example have a more structurally distance impressions of the central government, while the local government is close and with a variety of structural contact points. So distant versus close interaction would influence peoples' trust and risk perceptions.

In an organizational context a cultural perspective emphasizes informal norms, values and practices that have developed over time through a process of institutionalization, resulting from mutual adaptation to internal and external pressure (Selznick, 1957). Such a perspective is relevant when analyzing crisis managementrelated actions within organizational/institutional frameworks, like public organizations, but must be adapted when the focus is on the risk perceptions of citizens. The connotations of such a perspective are related to governance legitimacy. Governance legitimacy may contain general support and trust factors, but also distinct variety in perceptions based on regional/local cultures, social context, policies, type of risk, demography, etc. (Christensen, Lægreid, \& Rykkja, 2016).

Based on a combination of the perspectives and discussion of the central concepts and relationships, and focusing on individual citizens and their risk perceptions, provides insights into the context of trust relationships and our three types of trust trust in central government, trust in local government and social trust. Citizens in China who trust central government may on the one hand be people who know about the 
structure and workings of the central government, i.e. they know about governance capacity for preventing and handling risks. But they may also trust the government because they trust the party (Rothstein, 2014). Citizens' trust in local government with respect to crisis management is probably based more on personal knowledge of local incidences and crises. But, it is also likely that that such trust (or lack of it) is based on more personal knowledge of the dealings of the party locally, for example the extent of local corruption.

If we focus on crisis management and take into account the fact that overall the Chinese trust central more than local government, this could on the central level be based on high diffuse support (for the party) and high specific support for a central government that is visible and often plays a leading role in crisis management, frequently supported by strong symbols (Baekkeskov \& Rubin, 2017). On the local level trust may be low because people on the one hand see party leaders as corrupt and on the other because they have had negative experiences with prevention and handling of local crises (Christensen \& Ma, 2017).

Based on this we can formulate two hypotheses:

H1 - The more citizens trust central government the less they will perceive societal risks.

H2 - Trust in local government leads to less perceived risks.

However, how does general low trust in local government in China relate to perceived risks? If citizens base their perceptions on a combination of low diffuse and specific support, they may anyhow see a lot of potential risks. This may indicate that the trust level must be above a certain threshold to have an effect on perceived risks.

Social trust is primarily a cultural variable of a general nature and reflects path-dependency and traditions, because it takes time to build up. As mentioned above, social trust reflects social capital (Putnam, 2000), i.e. some people have more resources than others, which presumably gives them a better understanding of how to reach out to others. Concerning societal security, they will both have more insight into how to use social networks in crises and how to reach out to and collaborate with public authorities. 
The hypothesis will accordingly be:

H3: The more citizens trust fellow citizens the less they will perceive societal risks.

\section{Methods}

\section{Context and sample}

We set out to examine the implications of government trust and social trust for citizens' risk perceptions in the context of China. Over the past two decades, China has witnessed a number of crises, e.g., the SARS crisis in 2003, the Wenchuan earthquake in 2008, the Sanlu infant milk powder contamination in 2008, the Tianjin explosion in 2015, and heavy air pollution (airpocalypse) in Beijing and other northern cities (Christensen \& Ma, 2017). These and other crises have seriously undermined public confidence in government capacity to prevent and handle emergencies, which is likely to have a general effect on citizens' perceptions of social risks.

To test the above hypotheses, we use a 2013 randomly sampled and face-to-face citizen survey conducted in thirty provincial capital cities in China, with a total of more than 6000 respondents. The sample was taken from thirty major cities in China, including four municipalities (Beijing, Tianjin, Shanghai, and Chongqing), twenty-two provincial capital cities (e.g., Guangzhou), and the capital cities of the four autonomous regions (e.g., Urumqi). ${ }^{2}$ These cities are regional hubs with a high level of social risk, which gives us an appropriate context in which to investigate residents' concerns about various risks.

The survey was conducted in January 2013 by a well-established survey company based in Beijing. A multi-stage stratified random sampling method was used to select respondents to participate in the survey. The quota sample size was proportional to the total population size of each city, with samples of 300,250,200, and 150 for cities with populations of more than 10 million, from 5 to 10 million, from 2 to 5 million, and fewer than 2 million, respectively. The survey first proportionally sampled the

\footnotetext{
${ }^{2}$ Lhasa, the capital of Tibet, was excluded from the sample because survey data were unavailable.
} 
administrative districts in each city by share of total population, each of which was then divided into five subdistricts. The families and specific persons to be interviewed were then randomly selected in each subdistrict. Those selected were aged between 18 and 60 and had resided in the sampled city for at least one year. In sum, 6,259 people responded to the survey, with a response rate of 8.85 percent.

\section{Risk perceptions}

The data set includes a group of items on citizens' perceptions of social risks. The respondents were asked "Do you often worry about the following problems in your ordinary life?" The nine categories listed were crime, traffic accidents, fire/flood, public disorder, food safety, drug safety, epidemics, mafias and gangs, and environmental pollution. While this did not cover all possible risks, it facilitated a comprehensive examination of citizens' risk perceptions.

The respondents were asked to rate their risk perception on a five-point Likert scale ranging from 1 ("Not worried") to 5 ("Very worried"). Citizens' perceptions of different kinds of risks may be affected by different variables, and our interest in this study is to obtain a general picture of risk perceptions. While the survey items are not directly related to crisis management, citizens' concerns over these risks are relevant and may be largely shaped by their trust in government and social trust.

We ran an exploratory factor analysis to ensure internal consistency in measuring risk perceptions, which generated two factors (see Table 1). Principal component factors and oblique promax rotation are used in factor analysis to allow for correlations among risk components. Two factors with Eigenvalue larger than 1 are retained. Crime, traffic accidents, fire/flood, public disorder, epidemics, and mafias and gangs were clustered in one factor, while food safety, drug safety, and environmental pollution constituted the other. The first factor was labeled public emergencies, and the second, threats to public health. We used average values of indicators to measure the two components, and the use of factor scores generated similar results. 
Insert Table 1 about here

\section{Trust variables}

Government trust. Citizens' trust in central and local government was gauged by two separate five-point Likert scale items: "Central government policies are generally trustworthy". "Local government policies are generally trustworthy". Possible responses to the two items ranged from 1 (Strongly disagree) to 5 (Strongly agree). The two items are primarily about citizen trust of policy intentions (i.e., legitimacy) instead of generic trust of policy outcomes (i.e., capabilities), which may underestimate the effects of government trust.

Social trust. To measure social trust, we used a very relevant and innovative item. The respondents were asked "Would you consider giving the keys to your house to your neighbors in case of emergency, if you are going out of town for a period?" The respondents who said "yes" were coded 1 , those who said "no" were coded 0 . Given the expansion of cities and influx of migrants in recent decades, residents in Chinese cities often do not know their next-door neighbors. Communities are often made up of strangers without strong personal ties, frequent interactions, or reciprocal exchanges. The item used to gauge social trust was designed to mitigate social desirability bias, which may arise if more conventional survey questions such as "Do you trust strangers?" are used (Tao et al., 2014).

\section{Control variables}

We included a set of mostly demographic variables that may affect risk perceptions, including gender, age, education, occupation, affluence, religious belief, civil status, media exposure, and political ideology. A demographic perspective has traditionally been used in studies of how representative bureaucracies are and the effects of this (Christensen \& Lægreid, 2009; Meier, 1993; Pfeffer, 1983; Selden, 1997). The focus has been both on individual demographic characteristics or relational ones, i.e. the 
significance of cohorts and groups in certain organizational units (Christensen \& Lægreid, 2005). In studies of citizens and their dealings with and perceptions of public authorities, it is primarily individual characteristics that are of significance (Kampen, Van de Walle, \& Bouckaert, 2006). In particular, studies of trust in government have been connected to social background (Bennett \& Bennett, 1990). The reasoning is that the preconditions for trust, whether of a general or specific nature (Easton, 1965a), differ between social groups, related both to procedural and output features, reflecting differences in both knowledge and values.

What are some of the expectations we can have about the relationships between demographic variables and risk perceptions? First, concerning gender, we primarily expect women to be more worried about societal risks than men. Women have much more exposure to societal risk on a micro-level in their daily life, particularly in societies like China where relatively more women are home-makers (Liu \& Ma, 2016). And they may accordingly worry more because they feel responsible for the whole family. On the other hand, women normally support and trust the public sector more than men (Christensen \& Lægreid, 2005). Gender was measured by a dummy, with male coded as 1 and female as 0 .

Concerning age, we know from various studies that older people trust government more than younger people and are more collectively oriented. But older people have more experience with and insights into societal risks, which makes them worry more (Christensen, Fimreite, \& Lægreid, 2011). With declining physical and mental health, older people is more vulnerable to social threats. This may lead to the expectation that older people will perceive more societal risks than younger people. Age was gauged by an ordinal variable ranging from $0(18-25)$ to $7(>55)$.

Education or educational level may be differently correlated with perceived societal risks. People with higher education will have more resources and intelligence, hence will know more about how society works, including the risks, but will also know better how to deal with those risks (Kampen, Van de Walle, \& Bouckaert, 2006). But overall, we would expect people with higher education to be relatively more concerned about societal risks. Education was operationalized by an ordinal variable, ranging from 0 
(Primary school and below) to 4 (University and above).

Occupation status may also be relevant for risk assessment (Christensen, Fimreite, \& Lægreid, 2011). Students, the unemployed or people on benefits of various kinds will overall rely more on government and trust it more, which may lead to fewer worries about societal risks. Employed people will, on the contrary, perceive more societal risks, because of relative more exposure to risks. Occupational status was divided into two categories, and we created a dummy of unemployment.

Civil status. People who are married and/or have a family of their own are on the one hand more integrated in society and probably more dependent on the public sector, but on the other hand more vulnerable to societal risks. This may make them more worried about societal risks. The marital or civil status of the respondents was classified into five groups: (1) Married, (2) Widow/widower, (3) Separated/divorced, (4) Unmarried and single, and (5) Unmarried but living with partner. We created a dummy of married, using the other four types as the reference group.

A family income may signify that people have extra resources to protect themselves (Liu \& Ma, 2016). We, accordingly, expect people with a high income to have a lower perception of societal risks. Monthly family income, which is measured by an ordinal variable ranging from 0 (non-fixed income) to 16 (>40,000 RMB).

Children. People who are under age (e.g., infants and teenagers) are relatively more prone to various risks, and respondents with children in the home are more likely to be concerned about social risks. For instance, parents are more worried about food safety than those without children at home (Liu \& Ma, 2016). In the survey the respondents were asked to indicate whether there are children aged 6 to 16 at home, and we include this dummy in the model. ${ }^{3}$

Religious belief normally indicates more societal integration, whether generally or related to specific groups. This will probably lead to more trust in government and more in other people. We would therefore expect that the more religious people are, the less they perceive societal risks. Religious belief was determined by the question: "Do you

\footnotetext{
${ }^{3}$ We thank one anonymous reviewer for suggesting us to include this variable.
} 
usually participate in religious activities?" The scale of responses ranged from 1 (Never) to 5 (Often), with higher values denoting more frequent religious observance.

Party membership. China is governed by one ruling party (Chinese Communist Party $(\mathrm{CCP})$ ), and party members are relatively privileged in the authoritarian regime. In China being a party member means both being close to the government and potentially having diverse social benefits. We would therefore expect party members to worry less about societal risks. Political ideology was measured by the respondents' party affiliation, with the following categories: (1) Chinese Communist Party (CCP) member, (2) Member of a democratic party, (3) Communist Youth League (CYL) member, and (4) Other. We merged the first three categories to create a dummy of party membership, since the majority of the respondents (78.32 percent) were non-party affiliated.

Media exposure is not really a demographic variable, but may connect to several of the above mentioned. Citizens exposed to media coverage of societal risks are likely to perceive them as more threatening (Wahlberg \& Sjoberg, 2000). So even though greater media exposure may correlate with higher education and income, we would overall expect high media exposure to engender more worry about societal risks. To measure media exposure we asked one question with a number of options: "Which channels do you primarily use to get access to domestic and international news?" The respondents were asked to rate how frequently they used internet news portals, online forums and blogs, microblogs, newspapers and magazines, TV, and chats with friends and colleagues. In each case respondents could select one of three categories: (0) Almost never, (1) Occasionally, and (2) Almost every day. We aggregated these items to develop an index of media exposure, which is expected to be positively correlated with risk perceptions. While we can distinguish mass media from social media, it is beyond the scope of this study.

Apart from individual-level demographic variables, we control for several city-level variables that may affect citizens' risk perceptions. First, we include per capita GDP to gauge urban affluence, since economic underdevelopment is usually related to various risks. Second, we control for total population size, because large cities are more prone to risk spillover. Third, we include the percentage of migrants, as migration is often 
associated with social stability risks. We also include administrative rank of the cities, which partially reflect urban resilience to social risks. We create two dummies for four municipalities and ten sub-provincial cities (e.g., Guangzhou), and use prefecture-level cities as the reference group. Lastly, given that geographic locations of cities may affect the susceptibility of some risks (e.g., flooding), we include city dummies in models. We follow geoscientists' suggestions (Gao, 2003) to classify the cities into three regions by their vulnerability to various natural disasters, including coastal, central, and western clusters. We use central cities as the reference group and create two dummies for coastal and western ones. ${ }^{4}$ The 2012 data on GDP are from the National Bureau of Statistics and the population and migration data are from the 2010 national census.

\section{Model specification}

The survey data used in this study are characterized by a multilevel structure, with individual respondents nested in cities. Such a data structure violates the assumptions of ordinary least square (OLS) (e.g., independence), and a multilevel model or hierarchical linear model (HLM) is more appropriate in model specification. The multilevel model is superior in simultaneously estimating context- and individual-level effects, and we use it to estimate the effects of government and social trust on citizens' perceptions of social risks while simultaneously controlling for individual-level demographic and socioeconomic variables.

Citizens' risk perceptions are Level 1 variables, and city-level variables are referred to as Level 2 variables. Our focus here is to estimate the effects of Level 1 independent variables on the dependent variable, and we center the Level 1 independent variables by their mean within each city while centering the Level 2 variable by its grand mean. While the model specification is different from conventional OLS, the regression coefficients and other parameters could be interpreted in a similar manner.

\footnotetext{
${ }^{4}$ We thank one anonymous reviewer for suggesting us to include these dummies.
} 


\section{Results}

\section{Descriptive statistics}

As shown in Table 1, the respondents are mostly concerned about food safety (Mean=4.3) and drug safety (4.2), followed by environmental pollution (3.9), all pertinent to public health risks. They are less concerned about traffic accidents (3.8), SARS, bird flu, and other epidemics (3.5), and they are least worried about crime, fire/flood, public disorder, epidemics, and mafias and gangs. In other words, the respondents are more concerned about public health threats (4.1) than public emergencies (3.5). The sampled cities vary substantially in terms of the two risk factors (see Appendix Figure 1).

In terms of government trust, the respondents trust central government (Mean=3.6) more than local (3.4) (see Table 2). While the respondents generally trust the government, the level of government trust is not very high. The results show that 30.2 of respondents trust central government more than local, while 16.7 percent are just the opposite. About half of respondents (53.1 percent) trust local and central governments equivalently. Our findings are consistent with prior surveys revealing hierarchical trust among Chinese citizens (Chen, 2017; Li, 2016; Wu \& Wilkes, 2017). The sampled cities vary substantially in terms of the two government trust variables (see Appendix Figure 2). With regard to social trust, we find that only 19.3 percent of the respondents trust their neighbors, whereas the majority are reluctant to entrust their property to neighbors. The findings suggest that social trust among urban residents is problematic.

Insert Table 2 about here

The bivariate relationships between the key individual-level variables suggest that citizens' trust in the central government is positively and moderately correlated with 
local government trust $(\mathrm{r}=0.57, \mathrm{p}<0.05) .{ }^{5}$ Central and local government trust is positively albeit weakly correlated with social trust $(r=0.046, p<0.05 ; \mathrm{r}=0.057, \mathrm{p}<0.05)$. We find that citizen perceptions of emergencies are only positively related to local government trust $(r=0.036, \mathrm{p}<0.05)$, and the correlation with central government trust is negative albeit nonsignificant $(\mathrm{r}=-0.003, \mathrm{p}>0.05)$. Citizen perceptions of public health risks are positively related to both central and local government trust variables $(r=0.071$, $\mathrm{p}<0.05 ; \mathrm{r}=0.055, \mathrm{p}<0.05)$. The risk perception factors are not significantly related to social trust $(r=0.002, p>0.05 ; r=-0.007, p>0.05)$. The mean values of variance inflation factor (VIF) across models below are all much lower than 10, suggesting multicollinearity is not a severe threat.

\section{Multilevel model estimates}

We first report the result of the null model, which helps us estimate the share of variance explained by each level of variables. We find that the intraclass correlation (ICC) is 0.1336 , which means that roughly 13.4 percent of the total variance in the first risk perception factor is attributable to Level 2 variables. The ICC for the second risk perception factor is 0.1592 , suggesting that 15.9 percent of its total variance could be attributed to Level 2 variables. The LR tests for the two null models $\left(\chi^{2}=745.86, p<0.01\right.$; $\left.\chi^{2}=863.09, \mathrm{p}<0.01\right)$ suggest that the variance explained by city-level variables is statistically significant, and it is more appropriate to use the multilevel model than OLS.

We estimate random intercept and fixed slope model (RIFSM) to examine the direct relationships of individual-level variables with risk perceptions (see Model 1 of Table 3). Statisticians recently have suggested using 0.005 as the P-value threshold for statistical significance (Benjamin et al., 2017), and we follow this rule in this study and also use 0.05 as a conservative criterion. In line with $\mathrm{H} 1$, central government trust is negatively and significantly related to citizen perceptions of emergencies $(\beta=-0.05$, $\mathrm{p}<0.005$ ). In contrast to $\mathrm{H} 2$ and $\mathrm{H} 3$, both local government trust and social trust are

\footnotetext{
${ }^{5}$ The correlation matrices are cut to save space but are upon request from the authors.
} 
positively associated with emergency perceptions, but only the former is significant $(\beta=0.04, p<0.01)$, although on a lower level than central government trust. In terms of citizens' perceptions of public health risks, all three trust variables are positively correlated, and neither is significant. In a nutshell, only $\mathrm{H} 1$ is partially supported, while $\mathrm{H} 2$ and $\mathrm{H} 3$ are not supported by the evidence.

Insert Table 3 about here

As a robustness check, we also separately estimate the nine risk types by the same group of independent variables (see Table 4). The dependent variables are five-point Likert scale items, and it is suitable to use multilevel ordinal logit models. We also use multilevel linear and logit models (merging "Very worried" and "Worried" to create dummies), and the key results are substantially similar. ${ }^{6}$ We find that central government trust is negatively and significantly related to citizen perceptions of crime, public disorder, and mafias and gangs (odds ratios are reported). Its associations with traffic accidents and environmental pollution, however, are positive and significant. The results show that local government trust is positively related to citizen concerns of all nine types of risk, but only significant for crime, fire and flood, public disorder, and mafias and gangs. The findings reveal that social trust is positively and marginally significantly associated with fire and flood, public disorder, and mafias and gangs. While there are some variations, these results are by and large consistent with the above estimates.

Insert Table 4 about here

We controlled for a group of demographic variables that may affect risk perceptions,

\footnotetext{
${ }^{6}$ We thank one anonymous reviewer for suggesting us to separately estimate the models. The results are cut to save space but are upon request from the authors.
} 
and the results are largely consistent with our expectations. Ceteris paribus, female, elderly, and highly educated respondents are more concerned about social risks than young male respondents with little education. Unemployment, family income, civil status, children, and party membership are not statistically related to risk perceptions. The results show that religious belief is only negatively related to health threat perceptions $(\beta=-0.04, p<0.005)$. We find that respondents with a higher level of media exposure are more concerned about social risks. The city-level variables included in the models are all nonsignificant, suggesting their associations with public risk perceptions are not well supported. The estimates by separated risk types also generate substantially similar results of these control variables (see Table 4).

\section{Discussion}

\section{Analytical insights and policy implications}

The findings of this study reveal that risk perceptions can be divided into two categories; public emergencies and public health threats. It is useful to classify social risks for risk management and communication in differentiating situations (Slovic, 1987). Perceptions of public emergencies are more about acute and unexpected accidents, whereas the other category is more about chronic and specific threats to public health.

Second, we found that citizens' trust was not a generalized one, but differentiated (Easton, 1965b). People trusted more the central authorities than local government and scored relatively low on social trust. This may overall be problematic, because building a general, diffuse support or trust imply a number of interrelated elements (Bouckaert \& Van de Walle, 2001). Lacking such a generalist trust may further influence risk perceptions and participate in undermining peoples' will and ability to mitigate risks and support risk management and the governance capacities in fighting crises.

Third, we found that only central government trust is negatively correlated with citizens' perceptions of public emergencies, whereas local government trust is positively associated with risk perceptions. The results imply that citizens' trust in 
central government helps mitigate risk perceptions, particularly perceived public emergencies. Since citizens' overall trust in the central government is relatively higher than in the local government (Chen, 2017; Li, 2016; Wu \& Wilkes, 2017), this may help decrease their risk worries.

Although local government is at the forefront of crisis response and handling, citizens' trust in local government does not decrease risk perceptions. Contrary to our expectation, citizens who trust local government are more concerned about public emergencies. Why does trust in local government not decrease risk perceptions? A possible reason is that citizens are dissatisfied with local governments' underperformance in crisis management (Lu \& Xue, 2016), which results in a high level of risk perception. And, as indicated in the theory, the low overall trust in local government may further this, meaning one has to move beyond a certain threshold to change risk perceptions. It is also related that central leaders may strategically use local governments as "lightning rods" or scapegoats to avoid blames for crisis responses (Baekkeskov \& Rubin, 2017).

The question posed to the respondents about trust relates, however, more generally to how they trust central and local government policies, and not to trust in how societal risks are handled, which may be relevant for interpreting the results. The two government trust items are mainly about policy intentions (i.e., legitimacy) rather than policy outcomes (i.e., capabilities), but it is the central government making policy decisions (Wang \& Yu, 2017), which may partially explain the results mentioned above. Policies that are rather abstract and general are mostly made on the central level and known to citizens through information/propaganda from the central party organization (Zhu, Lu, \& Shi, 2013). This will probably more easily translate into a belief in the ability of the central level to handle societal risks. Policies on the local level mostly reflect centrally decided policies that local governments struggle to implement $(\mathrm{Li}$, 2016). Citizens are aware of this, which adds to their already established worries about whether local government will be able to handle societal risks. So trust in policies in general at the local level does not translate into a lower level of perceived societal risk.

Also, citizens who trust local government policies tend to be civically minded and 
follow the news closely, which may make them more worried about various types of social risk. Media exposure is positively related to both risk types, suggesting it could be a plausible explanation for the counterintuitive positive correlation between local trust and risk concern. ${ }^{7}$ But it is still a puzzle why it should lead to higher perceived risks, unless this group is simply more cynical because of its more knowledge about and bad experience of local handling of crises or more hopeful and therefore more disappointed.

We also find that social trust is positively albeit not significantly correlated with risk perceptions, contrary to our expectation. We expected social trust potentially to help boost reciprocal cooperation among social actors during and after crises, which may mitigate risk perceptions. But there may also be some arguments for the counter-intuitive result. First, since social trust is scoring so low, just like with trust in local government, may be the trust level has to be beyond a certain threshold to affect risk perceptions. Second, social interaction may not always be good news for crisis management. Social risks are communicated among people by word of mouth, and this may amplify risk perceptions (Kasperson, Renn, \& Slovic, 1988). Man-made accidents like stampedes may be a product of crowded cities. Rumors and fake information also emerges from social interaction (Zhu, Lu, \& Shi, 2013), which undermines citizens' trust in government actions and increases their fears about societal security.

The more general point here may combine two insights, namely that when peoples' individual experience are good, they tend to trust the government (Rothstein \& Steinmo, 2000), and that peoples' needs for and perceptions of public services tend to differ (Aberbach \& Rockman, 2000). In our case, personal experiences are related to local government and other people, because of proximity, resulting in low trust. High trust in central government is not build much on personal experiences but on more general impressions and is not leading to high overall diffuse support because of other trust mechanism on the local level (Easton, 1965b). Adding to this, there is a likelihood that people trusting local government and other people don't convert this into low risk

\footnotetext{
${ }^{7}$ We thank one anonymous reviewer for pointing out this explanation.
} 
perceptions because they have fewer needs related to risk management, because of more social resources (Christensen, Fimreite, \& Lægreid, 2011), something that also leads to cynicism.

We also showed that demographic variables are of significance for citizens' perceptions of risk, but probably for different reasons (Christensen, Fimreite, \& Lægreid, 2011; Christensen \& Lægreid, 2005). Women are probably more worried because of more exposure and wider family responsibilities. Old people are more worried because of experience, because they have seen many times how local crises are badly managed. People with higher education have a higher risk perception because they have more knowledge and greater insights into the risks of a modern society. More religious people are less concerned about societal risks, partly because they believe in human being's capacity in mitigating risks. High media exposure engenders more worry about societal risks, probably because people are influenced by negative news about risks.

The results reported in this study suggest that citizens' trust in central government can be leveraged to mitigate public risk perceptions. Although China's central government enjoys a relatively high level of trust among its constituency, its resilience and legitimacy have been undermined by rampant and high-profile corruption, nationwide food and drug safety scandals, persisting environmental pollution, and workplace accidents costing many lives (Wu, Yang, \& Chen, 2017). The importance of trust in central government for risk perceptions should be emphasized, and central governance capacity and legitimacy can be strengthened through more effective risk communication and crisis management (Chen, 2016).

While local governments suffer from an alarming deficit of trust, our findings suggest that trust in local government may actually aggravate citizens' risk perceptions. Social trust in the urban society of contemporary China has been substantially undermined (Tao et al., 2014), and endeavors to rebuild social trust may encounter difficulties in mitigating public risk perceptions. 


\section{Limitations and future research directions}

By nature this study is exploratory (hypothesis generating) rather than confirmatory (hypothesis testing), and it is limited in three respects, which call for future research. First, our trust variables are measured by single items. Future studies may draw on multiple items and theoretically grounded scales to gauge institutional and social trust (Grimmelikhuijsen \& Knies, 2015). The two government trust items are primarily about policy intentions (i.e., legitimacy) instead of policy outcomes (i.e., capabilities), which can be revised in future surveys. Social trust measure may be only appropriate for collectivistic societies, and it would be problematic from the standpoint of people from individualistic societies, i.e. a tension China is experiencing with its capitalistic and materialistic development in the last decades. Second, the data are from respondents in major cities in China, and the findings can be replicated and extended in medium and smaller regions in other contexts. The relationship between the government and the public in other democracies may be very different from that in authoritarian China (Christensen \& Aars, 2017), so it would be useful to retest our hypotheses in other contexts. Lastly, owing to data limitations, the study is a cross-sectional analysis. Citizens with higher levels of risk perception, for instance, may attribute risky situations to government underperformance, which undermines government trust. For instance, a recent study reveals that citizens' concerns about food safety have substantially undermined public trust in both central and local governments (Wu, Yang, \& Chen, 2017). We cannot eliminate such reverse causality threats, which may be originated through different mechanisms, and we call for longitudinal and experimental design to elicit the causality of the relationships.

\section{References}

Aberbach, J. D., \& Rockman, B. (2000). In the web of politics: Three decades of U.S. Federal executive. Washington D.C.: Brookings Institution Press.

Baekkeskov, E., \& Rubin, O. (2017). Information dilemmas and blame-avoidance strategies: From secrecy to lightning rods in Chinese health crises. Governance, 30(3), 425-443.

Beck, U. (1992). Risk society: Towards a new modernity. London: Sage. 
Benjamin, D., Berger, J., Johannesson, M., Nosek, B., Wagenmakers, E., \& et al. (2017). Redefine statistical significance. Human Nature Behavior., forthcoming.

Bennett, L. L., \& Bennett, S. E. (1990). Living with leviathan: Americans coming to terms with big government. Lawrence: University Press of Kansas.

Bouckaert, G., \& Van de Walle, S. (2001). Government performance and trust in government. Paper presented at the Paper presented at the EGPA Annual Conference, Vaasa, Finland.

Bovens, M. (2007). Analysing and assessing accountability: A conceptual framework1. European Law Journal, 13(4), 447-468.

Chen, D. (2017). Local distrust and regime support: Sources and effects of political trust in China. Political Research Quarterly, doi: 1065912917691360.

Chen, G. (2016). The politics of disaster management in China: Institutions, interest groups, and social participation. New York: Palgrave Macmillan.

Chen, W. (2013). The effects of different types of trust on consumer perceptions of food safety: An empirical study of consumers in Beijing municipality, China. China Agricultural Economic Review, 5(1), 43-65.

Christensen, D. A., \& Aars, J. (2017). Does democracy decrease fear of terrorism? Terrorism and Political Violence, 1-17.

Christensen, T., Fimreite, A. L., \& Lægreid, P. (2011). Crisis management: The perceptions of citizens and civil servants in Norway. Administration \& Society, 43(5), 561-594.

Christensen, T., \& Lægreid, P. (2005). Trust in government: The relative importance of service satisfaction, political factors and demography. Public Performance \& Management Review, 28(4), 487-511.

Christensen, T., \& Lægreid, P. (2009). Living in the past? Change and continuity in the norwegian central civil service. Public Administration Review, 69(5), 951-961.

Christensen, T., Lægreid, P., Roness, P. G., \& Røvik, K. A. (2007). Organization theory and the public sector: Instrument, culture and myth. Aldershot, UK: Ashgate.

Christensen, T., Lægreid, P., \& Rykkja, L. H. (2016). Organizing for crisis management: Building governance capacity and legitimacy. Public Administration Review, 76(6), 887-897.

Christensen, T., \& Ma, L. (2017). Coordination structures and mechanisms for crisis management in China: Rhetoric or reality? Paper presented at the The Conference "From the management of crisis to the governance of risk: Time for a paradigm shift?".

Cyert, R. M., \& March, J. G. (1963). A behavioral theory of the firm. Englewood Cliffs, NJ: Prentice-Hall.

De Jonge, J., van Trijp, J. C. M., van der Lans, I. A., Renes, R. J., \& Frewer, L. J. (2008). How trust in institutions and organizations builds general consumer confidence in the safety of food: A decomposition of effects. Appetite, 51(2), 311-317.

Easton, D. (1965a). A framework for political analysis. Englewood Cliffs, NJ: Prentice Hall.

Easton, D. (1965b). The political system: An inquiry into the state of political science. New York: Knopf. 
Egeberg, M. (2012). How bureaucratic structure matters: An organizational perspective. In B. G. Peters \& J. Pierre (Eds.), The sage handbook of public administration (pp. 157-168). London: Sage Publications.

Gao, Q. (2003). The distributions of natural disasters and the divisional disaster-countermeasures for China. Earth Science Frontier, 10(Suppl.), 258-264.

Grimmelikhuijsen, S., \& Knies, E. (2015). Validating a scale for citizen trust in government organizations. International Review of Administrative Sciences.

Kampen, J. K., Van de Walle, S., \& Bouckaert, G. (2006). Assessing the relation between satisfaction with public service delivery and trust in government: The impact of the predisposition of citizens toward government on evalutations of its performance. Public Performance and Management Review, 29(4), 387-404.

Kasperson, R. E., Renn, O., \& Slovic, P. (1988). The social amplification of risk: A conceptual framework. Risk Analysis, 8(2), 177-187.

Levi, M., \& Stoker, L. (2000). Political trust and trustworthiness. Annual Review of Political Science, 3(1), 475-507.

Li, L. (2016). Reassessing trust in the central government: Evidence from five national surveys. The China Quarterly, 225, 100-121.

Liu, P., \& Ma, L. (2016). Food scandals, media exposure, and citizens' safety concerns: A multilevel analysis across Chinese cities. Food Policy, 63, 102-111.

Lu, X., \& Xue, L. (2016). Managing the unexpected: Sense-making in the Chinese emergency management system. Public Administration, 94(2), 414-429.

Meier, K. J. (1993). Representative bureaucracy: A theoretical and empirical exposition. In J. L. Perry (Ed.), Research in public administration (Vol. 2, pp. 1-35). Greenwich CT: JAI Press.

Persson, T., Parker, C. F., \& Widmalm, S. (2017). Social trust, impartial administration and public confidence in eu crisis management institutions. Public Administration, 95(1), 97-114.

Pfeffer, J. (1983). Organizational demography. In L. L. Cummings \& B. M. Staw (Eds.), Research in organizational behavior (Vol. 5, pp. 299-357). Greenwich, CT: JAI Press.

Putnam, R. D. (2000). Bowling alone: The collapse and revival of the American community. New York: Simon \& Schuster.

Rothstein, B. (1998). Just institutions matter: The moral and political logic of the universal welfare state. Cambridge: Cambridge University Press.

Rothstein, B. (2014). The Chinese paradox of high growth and low quality of government: The cadre organization meets max weber. Governance, 28(4), 533-548.

Rothstein, B., \& Steinmo, S. (Eds.). (2000). Restructuring the welfare state: Political institutions and policy change. New York: Palgrave Macmillan.

Sapp, S. G., \& Bird, S. R. (2003). The effects of social trust on consumer perceptions of food safety. Social Behavior and Personality: an International Journal, 31(4), 413-421.

Schillemans, T. (2008). Accountability in the shadow of hierarchy: The horizontal 
accountability of agencies. Public Organization Review, 8(2), 175-194.

Selden, S. C. (1997). The promise of representative bureaucracy: Diversity and responsiveness in a government agency. New York: ME Sharpe.

Selznick, P. (1957). Leadership in administration. New York: Harper \& Row.

Siegrist, M., \& Cvetkovich, G. (2000). Perception of hazards: the role of social trust and knowledge. Risk Analysis, 20(5), 713-720.

Simon, H. A. (1957). Administrative behavior. New York: The Free Press.

Slovic, P. (1987). Perception of risk. Science, 236(4799), 280-285.

Tao, R., Yang, D. L., Li, M., \& Lu, X. (2014). How does political trust affect social trust? An analysis of survey data from rural China using an instrumental variables approach. International Political Science Review, 35(2), 237-253.

Van de Walle, S., \& Bouckaert, G. (2003). Public service performance and trust in government: The problem of causality. International Journal of Public Administration, 26(8), 891-913.

Wahlberg, A. A. F., \& Sjoberg, L. (2000). Risk perception and the media. Journal of Risk Research, 3(1), 31-50.

Wang, J., \& Yu, W. (2017). Government performance in the eyes of business: An empirical study of smes in China. Public Performance \& Management Review, 40(4), 701-721.

Wu, C., \& Wilkes, R. (2017). Local-national political trust patterns: Why China is an exception. International Political Science Review, doi: 0192512116677587.

Wu, X., Yang, D. L., \& Chen, L. (2017). The politics of quality-of-life issues: Food safety and political trust in China. Journal of Contemporary China, 1-15.

Yang, K., \& Holzer, M. (2006). The performance-trust link: Implications for performance measurement. Public Administration Review, 66(1), 114-126.

Yu, W., \& Ma, L. (2016). External government performance evaluation in China: Evaluating the evaluations. Public Performance \& Management Review, 39(1), 144-171.

Zhu, J., Lu, J., \& Shi, T. (2013). When grapevine news meets mass media: Different information sources and popular perceptions of government corruption in mainland China. Comparative Political Studies, 46(8), 920-946. 


\section{Tables and Figures}

Table 1. The descriptive statistics and factor analysis of risk perception components

\begin{tabular}{llcccc}
\hline Rank & \multicolumn{1}{c}{ Risks } & Mean & SD & $\begin{array}{c}\text { Factor 1 } \\
\text { Emergency }\end{array}$ & $\begin{array}{c}\text { Factor 2 } \\
\text { Health } \\
\text { threat }\end{array}$ \\
\hline 8 & Crime & 3.4 & 1.19 & 0.918 & -0.187 \\
5 & Epidemics & 3.5 & 1.16 & 0.510 & 0.326 \\
7 & Fire/flood & 3.4 & 1.18 & 0.849 & -0.029 \\
9 & Mafias and gangs & 3.3 & 1.23 & 0.753 & 0.087 \\
6 & Public disorder & 3.5 & 1.15 & 0.734 & 0.122 \\
4 & Traffic accidents & 3.8 & 1.06 & 0.691 & 0.089 \\
1 & Food safety & 4.3 & 0.96 & -0.089 & 0.955 \\
2 & Drug safety & 4.2 & 0.99 & -0.043 & 0.929 \\
3 & Environmental pollution & 3.9 & 1.05 & 0.200 & 0.648 \\
\hline & Eigenvalue & & & 4.937 & 1.105 \\
\hline
\end{tabular}

Note: Oblique promax rotation is used in factor analysis, and rotated factor loadings for the two factors are reported in the last two columns. Explained variance $=0.67, N=$ 6,179 . 
Table 2. Descriptive statistics of key variables

\begin{tabular}{lccccc}
\hline \multicolumn{1}{c}{ Variable } & $N$ & Mean & SD & Min & Max \\
\hline Factor 1: Emergency & 6,255 & 3.5 & 0.91 & 1 & 5 \\
Factor 2: Health threat & 6,255 & 4.1 & 0.86 & 1 & 5 \\
Central govt. trust & 6,054 & 3.6 & 0.97 & 1 & 5 \\
Local govt. trust & 6,015 & 3.4 & 0.97 & 1 & 5 \\
Social trust & 5,927 & 0.2 & 0.39 & 0 & 1 \\
Gender (Male=1) & 6,257 & 0.5 & 0.50 & 0 & 1 \\
Age & 6,257 & 2.9 & 2.21 & 0 & 7 \\
Education & 6,231 & 2.3 & 1.04 & 0 & 4 \\
Jobless & 6,184 & 0.02 & 0.13 & 0 & 1 \\
Married & 6,214 & 0.7 & 0.44 & 0 & 1 \\
Family income & 5,908 & 7.0 & 2.59 & 0 & 16 \\
Children & 6,246 & 0.3 & 0.43 & 0 & 1 \\
Religious belief & 6,189 & 1.5 & 0.93 & 1 & 5 \\
Media exposure & 6,257 & 6.2 & 2.71 & 0 & 12 \\
Party membership & 6,157 & 0.2 & 0.41 & 0 & 1 \\
City-level variables & & & & & \\
GDP per capita & 30 & 64961.1 & 20966.18 & 37592.7 & 106686 \\
Population size & 30 & 868.4 & 616.99 & 199.3 & 2884.6 \\
Migration & 30 & 26.1 & 10.17 & 8.9 & 47.9 \\
Provincial level & 30 & 0.1 & 0.35 & 0 & 1 \\
Sub-provincial level & 30 & 0.3 & 0.48 & 0 & 1 \\
East & 30 & 0.3 & 0.47 & 0 & 1 \\
West & 30 & 0.2 & 0.41 & 0 & 1 \\
\hline Note: The reference & & & & 0.49
\end{tabular}

Note: The reference group of civil status is widow/widower, separated/divorced, unmarried (single), and unmarried (partner). 
Table 3. Multilevel model estimates

\begin{tabular}{|c|c|c|}
\hline Variable & Model 1: Emergency & Model 2: Health threat \\
\hline Central govt. trust & $-0.05 * * *(0.02)$ & $0.02(0.01)$ \\
\hline Local govt. trust & $0.04 * *(0.02)$ & $0.02(0.01)$ \\
\hline Social trust & $0.05(0.03)$ & $0.01(0.03)$ \\
\hline Gender $($ Male $=1)$ & $-0.05 *(0.02)$ & $-0.08 * * *(0.02)$ \\
\hline Age & $0.02 * * *(0.01)$ & $0.04 * * *(0.01)$ \\
\hline Education & $0.03 *(0.01)$ & $0.04 * * *(0.01)$ \\
\hline Jobless & $-0.04(0.10)$ & $-0.07(0.09)$ \\
\hline Married & $0.00(0.03)$ & $0.03(0.03)$ \\
\hline Family income & $-0.01(0.01)$ & $-0.01(0.00)$ \\
\hline Children & $0.00(0.03)$ & $0.03(0.03)$ \\
\hline Religious belief & $0.01(0.01)$ & $-0.04 * * *(0.01)$ \\
\hline Media exposure & $0.01 *(0.01)$ & $0.02 * * *(0.00)$ \\
\hline Party membership & $0.04(0.03)$ & $0.01(0.03)$ \\
\hline GDP per capita & $-0.03(0.09)$ & $0.10(0.10)$ \\
\hline Population size & $-0.15(0.13)$ & $-0.04(0.14)$ \\
\hline Migration & $0.00(0.08)$ & $-0.07(0.10)$ \\
\hline Provincial level & $0.22(0.14)$ & $0.05(0.16)$ \\
\hline Sub-provincial level & $0.14 \#(0.08)$ & $0.09(0.10)$ \\
\hline East & $0.13(0.15)$ & $-0.03(0.17)$ \\
\hline West & $0.33 \#(0.18)$ & $0.13(0.20)$ \\
\hline Constant & $3.47 * * *(0.06)$ & $4.09 * * *(0.07)$ \\
\hline Variance (L2) & $0.10 * * *(0.03)$ & $0.13 * * *(0.03)$ \\
\hline Variance (L1) & $0.74 * * *(0.01)$ & $0.62 * * *(0.01)$ \\
\hline AIC & 13527.021 & 12635.660 \\
\hline $\mathrm{BIC}$ & 13678.169 & 12786.808 \\
\hline$N$ & 5280 & 5280 \\
\hline Number of groups & 30 & 30 \\
\hline
\end{tabular}

Note: Standard errors are in parentheses. AIC and BIC refer to Akaike's and Bayesian information criterion respectively. \# $\mathrm{p}<0.1, * \mathrm{p}<0.05, * * \mathrm{p}<0.01, * * * \mathrm{p}<0.005$. 
Table 4. Multilevel ordinal logit model estimates of separated risk types

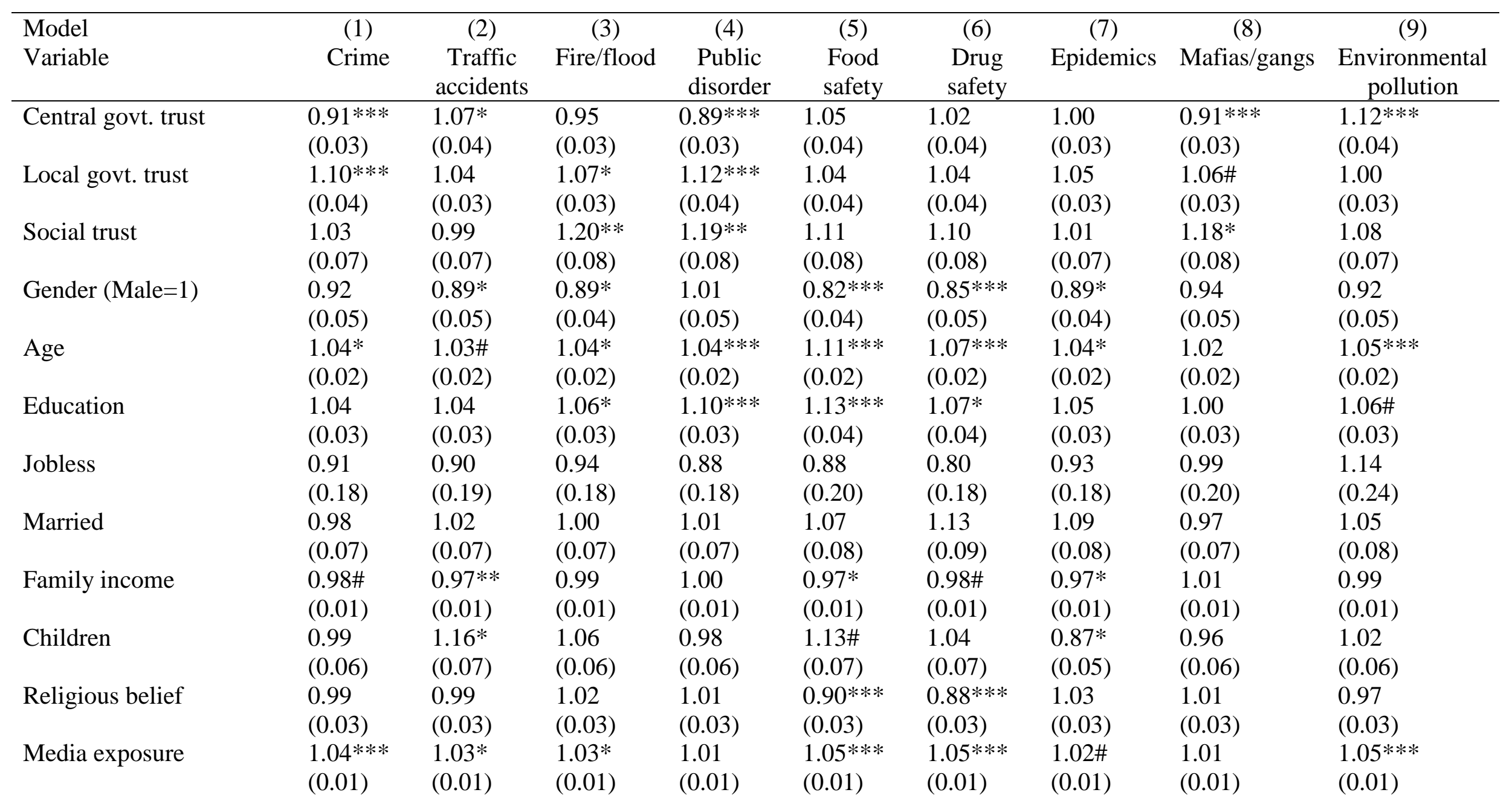




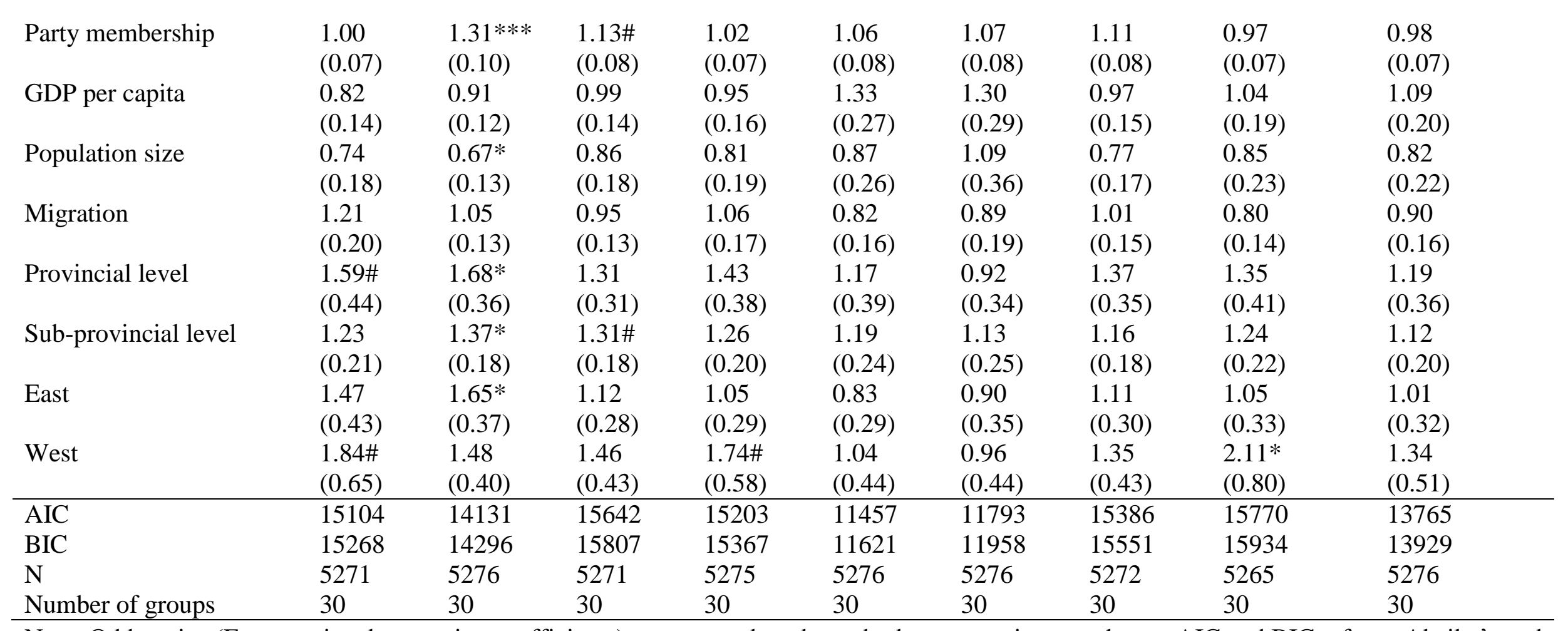

Note: Odds ratios (Exponentiated regression coefficients) are reported, and standard errors are in parentheses. AIC and BIC refer to Akaike's and

Bayesian information criterion respectively. \# $\mathrm{p}<0.1, * \mathrm{p}<0.05, * * \mathrm{p}<0.01, * * * \mathrm{p}<0.005$. 


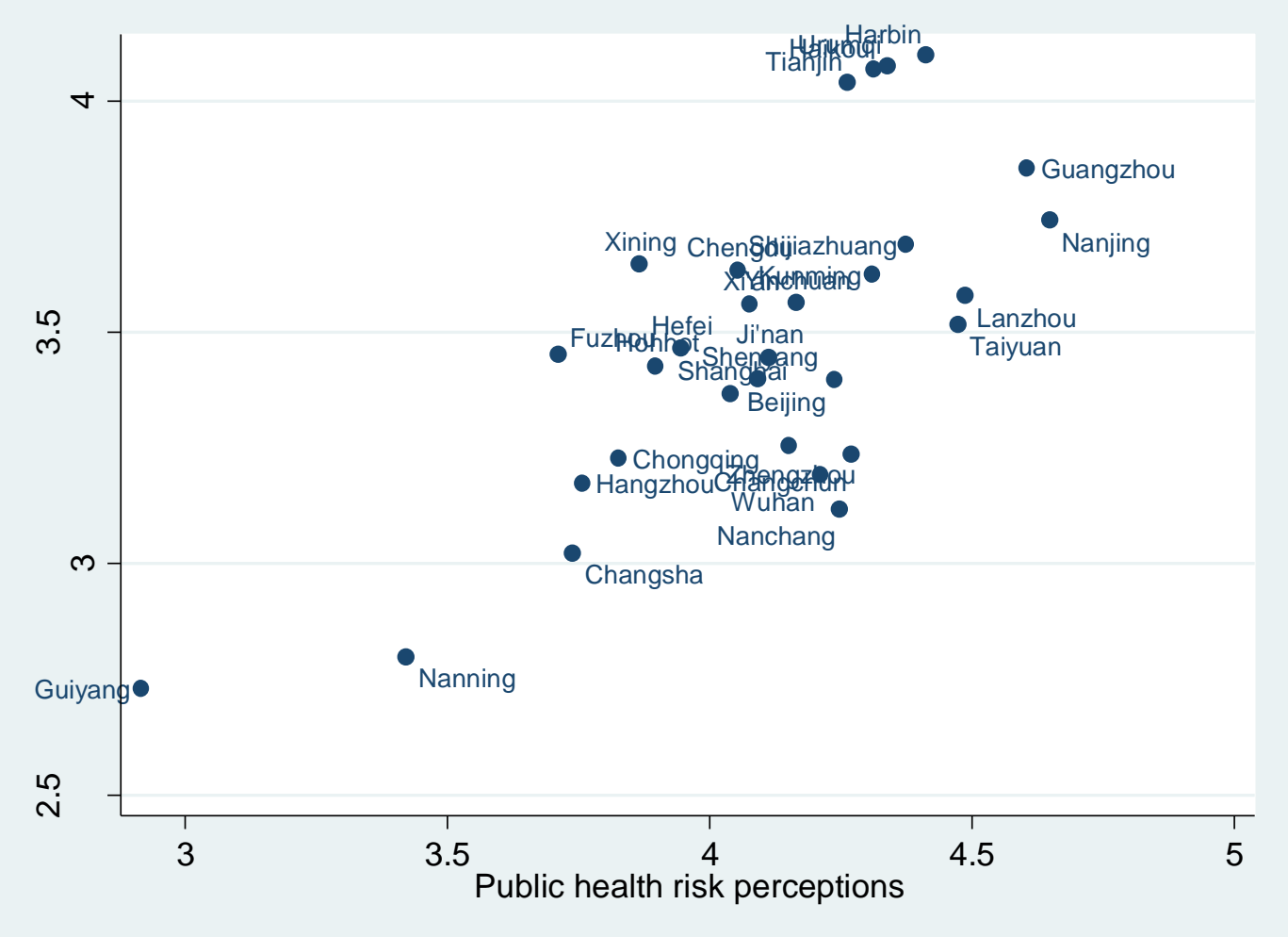

Appendix Figure 1. The two risk perception factors aggregated at city level 


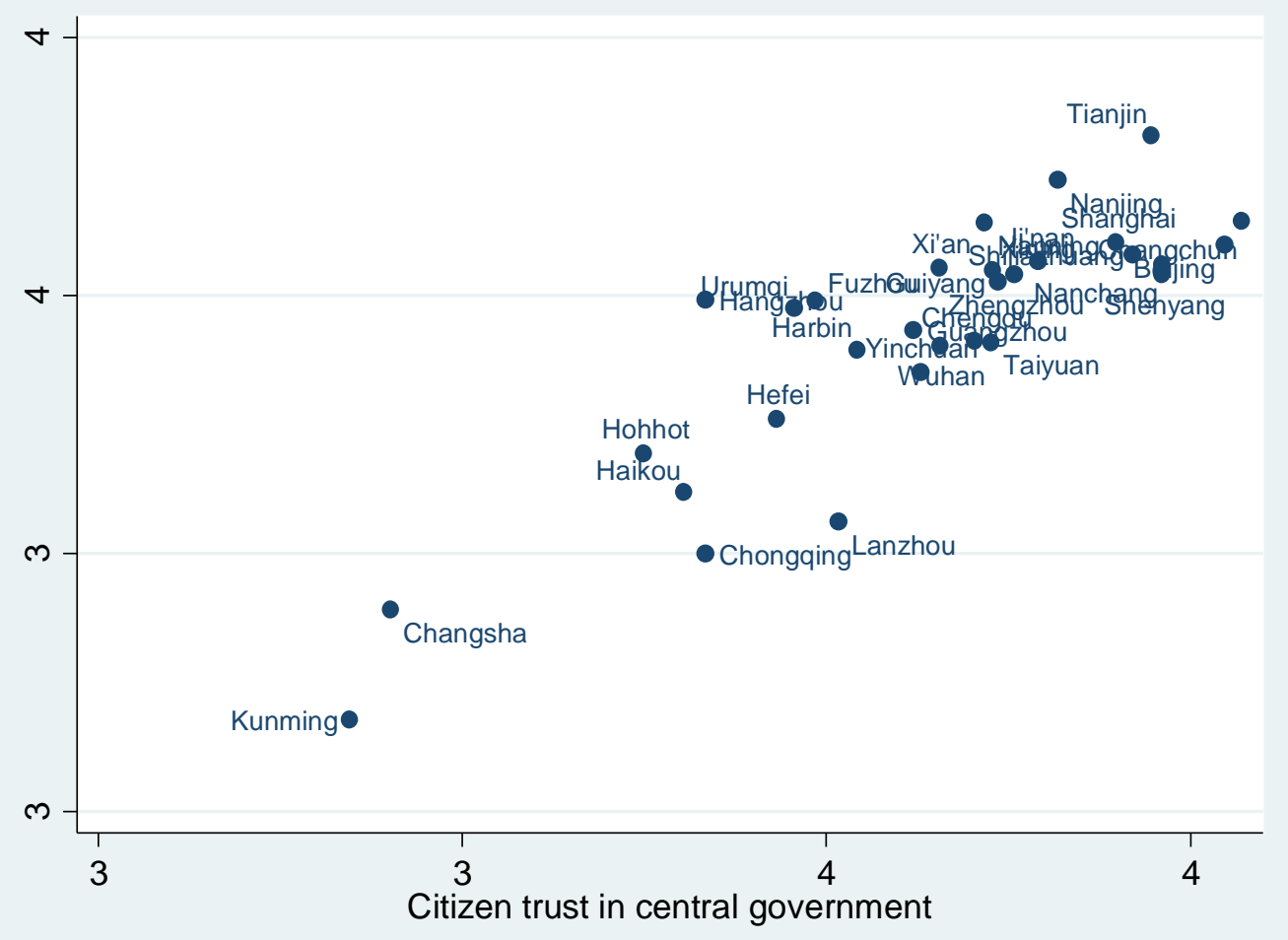

Appendix Figure 2. Central and local government trust aggregated at city level 